\title{
Observational study on patterns of neuromuscular blockade reversal
}

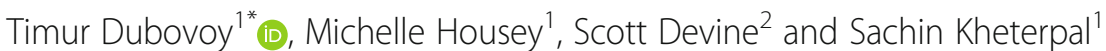

\begin{abstract}
Background: Using electronic health record data, we hypothesized that larger reversal doses are used for patients with deeper levels of neuromuscular blockade (NMB) as evidenced by the last recorded TOF measurement. We also examined if dosing regimens reflect current practice guidelines of using ideal body weight (IBW) for NMB agents and total body weight (TBW) for neostigmine.

Methods: This is a retrospective observational study of adult, ASA 1-4 patients who underwent general anaesthesia and received non-depolarizing NMB agents between 01/01/2004 and 12/31/2013. For the primary outcome, percentages of cases receiving neostigmine and median doses administered for each subjective train-of-four (TOF) category were calculated. Secondary analyses evaluated associations between NMB dosing and neostigmine administration based on Body Mass Index (BMI) categories.
\end{abstract}

Results: A total of 135,633 cases met inclusion criteria for the study. There was no clinically significant difference in median neostigmine dosing based on last TOF count prior to reversal administration: $37.5 \mathrm{mcg} / \mathrm{kg}$ for TOF of 4/4 vs. $37.9 \mathrm{mcg} / \mathrm{kg}$ for TOF of 0/4 for the total neostigmine dose. Significantly higher number of patients with lower TOF counts received additional neostigmine administration: $5.7 \%$ for 0/4 vs. $1.5 \%$ for $4 / 4$ TOF counts. The median times to extubation following neostigmine administration were clinically similar across TOF count categories. The median doses for neostigmine based on TBW decreased with higher BMI categories and were significantly different between the lowest and highest categories: $42.8 \mathrm{mcg} / \mathrm{kg}$ vs $30.8 \mathrm{mcg} / \mathrm{kg}$ for total doses $(p<.0001)$ respectively. The percentages of cases requiring reversal in addition to the initial dose increased with increasing BMI categories and were $2.1 \%$ for BMI $<18$ vs. $3.3 \%$ for BMI $\geq 40$. The total median dose of NMB agents in ED95 equivalents per IBW increased from 2.9 in the Underweight category to 4.2 in the Class III Obese category. The majority of patients in the pancuronium subgroup received very low ED95 equivalent dose of 0.1 and did not require reversal. Patients receiving cisatracurium were given significantly higher median ED95 equivalent dose of 5.6 vs 2.8-3.9 compared to other intermediate acting NMB agents, while receiving clinically similar doses of neostigmine.

Conclusions: Neither neostigmine dosing nor times to extubation were affected by the depth of the neuromuscular blockade prior to reversal. The need for additional reversal, or rescue, correlated strongly with the depth of NMB. There was significant variability in neostigmine dosing across the BMI categories. Underweight patients received relatively lower NMB doses while simultaneously receiving relatively higher reversal doses, and the opposite was true for patients with $\mathrm{BMI}>40$.

Keywords: Neuromuscular blockers, Neostigmine, Neuromuscular blockade reversal

\footnotetext{
* Correspondence: tdubovoy@med.umich.edu

'Department of Anaesthesiology, University of Michigan Medical School, CVC

4172, 1500 East Medical Centre Drive, Ann Arbour, Ml 48109, USA

Full list of author information is available at the end of the article
}

(c) The Author(s). 2016 Open Access This article is distributed under the terms of the Creative Commons Attribution 4.0 International License (http://creativecommons.org/licenses/by/4.0/), which permits unrestricted use, distribution, and reproduction in any medium, provided you give appropriate credit to the original author(s) and the source, provide a link to the Creative Commons license, and indicate if changes were made. The Creative Commons Public Domain Dedication waiver (http://creativecommons.org/publicdomain/zero/1.0/) applies to the data made available in this article, unless otherwise stated. 


\section{Background}

Non-depolarizing neuromuscular blockade (NMB) is commonly used to facilitate tracheal intubation and surgical conditions in patients undergoing general anaesthesia. It remains a mainstay of a balanced anaesthetic technique despite advances in short acting volatile and intravenous anaesthetics. Our understanding of the prevalence and impact of residual postoperative NMB has been greatly expanded in recent years $[1,2]$. Even mild levels of residual NMB decrease objective measures of pulmonary function, increase the risk of aspiration and airway obstruction, and worsen patient recovery experience [3-6]. Residual neuromuscular blockade continues to be a widespread problem, affecting greater than $50 \%$ of patients receiving NMB in normal practice, even despite qualitative neuromuscular monitoring and the use of neostigmine [7].

Although overwhelming majority of anaesthesiologists surveyed in Europe and the United States believe that either subjective or quantitative train-of-four (TOF) monitoring may improve NMB management [8], neither modality has been accepted as standard of care for patients receiving neuromuscular blocking agents. Among reasons cited for this lack of adoption of monitoring standards is significant practice variation in $\mathrm{NMB}$ management that exists between countries, hospitals, and individual practitioners [8, 9]. For example, according to Naguib et al. [8], "surveys in Denmark, Germany, the United Kingdom, and Mexico have suggested that only $43,28,10$, and $2 \%$ of clinicians respectively, routinely use neuromuscular monitors of any kind." In addition to practice variations in NMB monitoring, there are significant differences in the use of reversal agents at the end of a surgical procedure. In their response to a survey, $82 \%$ of European and $65 \%$ of American practitioners have reported that they did not routinely administer a reversal agent following use of non-depolarizing NMB drugs [8]. Current experts' opinions suggest that $\mathrm{NMB}$ monitoring should guide administration of $\mathrm{NMB}$ agents [1, 4] as well as NMB reversal agents [10, 11]. However, a wide gap continues to exist between experts' recommendations and current clinical practice of monitoring and NMB antagonism $[9,12]$. Presently available data on patterns of clinical practice are mainly limited to small (<1000 patients) observational studies [13] and survey results [8]. There are no recent data describing the routine practice patterns of reversal and its relationship to TOF monitoring. A better understanding of practice patterns is needed in order to guide future recommendations and target efforts to improve clinical practice and patient safety.

We used a large, granular intraoperative health record dataset to identify current practices in neostigmine reversal. The primary objective of this study was to assess whether dosing of neostigmine is related to the use of subjective train-of-four (TOF) monitoring. We hypothesized that reversal dosing is based upon the last recorded subjective TOF assessment, with larger doses used for patients with deeper levels of NMB as evidenced by lower TOF counts. We also examined whether dosing regimens reflect current practice guidelines of using ideal body weight (IBW) for NMB agents $[6,14-16]$ and total body weight (TBW) for neostigmine $[14,17,18]$.

\section{Methods}

\section{Study design and setting}

This retrospective observational study of adult, ASA 1-4 patients who underwent general anaesthesia and received non-depolarizing $\mathrm{NMB}$ agents at the University of Michigan between 01/01/2004 and 12/31/2013. This study received approval from the University of Michigan Institutional Review Board (HUM00091819). The informed consent was waived since all identifiable patient elements were removed prior to data analysis. We excluded patients who were intubated prior to OR arrival, patients transported to ICU following surgical procedure, cardiac surgery, lung or liver transplantation, cases where neostigmine was administered to facilitate intraoperative neurologic monitoring with subsequent redosing of NMB agents, and patients with myasthenia gravis or those receiving pyridostigmine therapy. Monitoring of the neuromuscular blockade and TOF counts were measured using the MiniStim ${ }^{\circ}$ MS-IV (Life-Tech, Stafford, TX) peripheral nerve stimulator. All data for this study was gathered from the local University of Michigan Health System (UMHS) anaesthesia information management system (AIMS) and electronic health record (EHR) (Centricity ${ }^{\circ}$, General Electric Healthcare, Waukesha, WI). Basic patient anthropometrics, including patient age, gender, body mass index (BMI), ASA classification, emergent classification, and procedural information including case duration and surgical service were extracted from the EHR. In addition, we collected dose and time of administration information for neostigmine and all non-depolarizing NMB drugs: vecuronium, rocuronium, atracurium, cisatracurium, and pancuronium. We converted the doses of neuromuscular blockers to effective doses required to reduce the maximum twitch height by $95 \%$ in $50 \%$ of the population (ED95 equivalents), corrected for ideal body weight $[6,19,20]$. The following conversions were used: vecuronium $0.05 \mathrm{mg} / \mathrm{kg}$, rocuronium $0.3 \mathrm{mg} / \mathrm{kg}$, atracurium $0.26 \mathrm{mg} / \mathrm{kg}$, cisatracurium $0.05 \mathrm{mg} / \mathrm{kg}$ and pancuronium $0.07 \mathrm{mg} / \mathrm{kg}$. Weight correction for neostigmine was performed using total body weight (TBW) [14, 17, 18]. Extubation times for all included cases were extracted as well. 
Table 1 Patient and Case Characteristics

\begin{tabular}{|c|c|c|}
\hline Patient/Case characteristics & $\begin{array}{l}\text { Did not receive } \\
\text { neostigmine }\end{array}$ & $\begin{array}{l}\text { Received } \\
\text { neostigmine }\end{array}$ \\
\hline Total $N=135,633$ & $\begin{array}{l}N=18,510 \\
(13.6 \%)\end{array}$ & $\begin{array}{l}N=117,123 \\
(86.4 \%)\end{array}$ \\
\hline $\mathrm{Age}^{\mathrm{a}}$ & $51 \pm 18$ & $52 \pm 17$ \\
\hline Surgical case duration (minutes) ${ }^{\mathrm{b}}$ & $144[87,238]$ & $113[69,177]$ \\
\hline Emergent surgery & $835(4.5)$ & $6095(5.2)$ \\
\hline \multicolumn{3}{|l|}{ ASA status } \\
\hline ASA class 1 or 2 & $10,976(59.3)$ & $68,910(58.8)$ \\
\hline ASA class 3 or 4 & $7534(40.7)$ & $48,213(41.2)$ \\
\hline \multicolumn{3}{|l|}{ Gender } \\
\hline Male & $9484(51.2)$ & $63,165(53.9)$ \\
\hline Female & $9026(48.8)$ & $53,957(46.1)$ \\
\hline \multicolumn{3}{|c|}{ World Health Organization BMI categories } \\
\hline Underweight, BMI <18.5 & $481(2.7)$ & $2456(2.2)$ \\
\hline Normal Weight, BMI 18.5-24.9 & $5466(30.8)$ & $3,2491(28.7)$ \\
\hline Overweight, BMI 25.0-29.9 & $5509(31.0)$ & $35,302(31.2)$ \\
\hline Class I Obesity, BMI 30.0-34.9 & $3346(18.8)$ & $22,634(20.0)$ \\
\hline Class II Obesity, BMI 35.0-39.9 & $1645(9.3)$ & $11,321(10.0)$ \\
\hline Class III Obesity, BMI $\geq 40$ & $1326(7.5)$ & $8973(7.9)$ \\
\hline
\end{tabular}

Last Recorded TOF

\begin{tabular}{|c|c|c|}
\hline $0 / 4$ & $347(1.9)$ & $3557(3.0)$ \\
\hline $1 / 4$ & $478(2.6)$ & $6987(6.0)$ \\
\hline $2 / 4$ & $510(2.8)$ & $7751(6.6)$ \\
\hline $3 / 4$ & $425(2.3)$ & $7170(6.1)$ \\
\hline $4 / 4$ & $4187(22.6)$ & $82,457(70.4)$ \\
\hline Undocumented & $12,563(67.9)$ & $9201(7.9)$ \\
\hline \multicolumn{3}{|l|}{ Surgical service } \\
\hline Dental & $734(4.0)$ & $2904(2.4)$ \\
\hline General & $2275(12.3)$ & $20,532(17.5)$ \\
\hline Gynecology & $1000(5.4)$ & $11,742(10.0)$ \\
\hline Neurology & $1937(10.5)$ & $9395(8.0)$ \\
\hline Ophthalmology & $443(2.4)$ & $1630(1.4)$ \\
\hline Orthopedics & $2843(15.4)$ & $18,273(15.6)$ \\
\hline Other & $1296(7.0)$ & $8763(7.5)$ \\
\hline Otolaryngology & 3691 (19.9) & $8452(7.2)$ \\
\hline Plastics & $1492(8.1)$ & $7814(6.7)$ \\
\hline Radiology & $304(1.6)$ & $2056(1.8)$ \\
\hline Thoracic & $533(2.9)$ & $5754(4.9)$ \\
\hline Transplant & $419(2.3)$ & $4810(4.1)$ \\
\hline Urology & $1093(5.9)$ & $10,657(9.1)$ \\
\hline Vascular & $450(2.4)$ & $4341(3.7)$ \\
\hline \multicolumn{3}{|c|}{ Neuromuscular blockade agent ${ }^{c}$} \\
\hline Atracurium & $1435(7.8)$ & $4528(3.9)$ \\
\hline Cisatracurium & $3613(19.5)$ & $17,892(15.3)$ \\
\hline
\end{tabular}

Table 1 Patient and Case Characteristics (Continued)

$\begin{array}{lll}\text { Pancuronium } & 1402(7.6) & 657(0.6) \\ \text { Rocuronium } & 1867(10.1) & 7069(6.0) \\ \text { Vecuronium } & 10,720(57.9) & 88,526(75.6) \\ \text { Multiple NMBAs } & 521(2.8) & 1544(1.3) \\ \text { Succinylcholine with NMBA } & 5891(31.8) & 28,608(24.4)\end{array}$

ASA American Society of Anaesthesiologists, BMI body mass index, TOF trainof-four, NMBA neuromuscular blockade agent

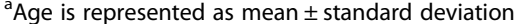

${ }^{\mathrm{b}}$ Surgical case duration is non-parametric and presented as median $\left[25^{\text {th }}\right.$ to $75^{\text {th }}$ percentile]

${ }^{\mathrm{C}}$ Cases may have received more than one type of neuromuscular blocking agent

\section{Statistical analysis}

All statistical analyses were performed using SPSS $^{\circ}$ version 21 (Armonk, NY) and $\mathrm{SAS}^{\circ}$ software, version 9.3 (Cary, NC). Missing data for each covariate were evaluated - only case duration was missing more than $10 \%$ (21.1\%). Patients with missing or invalid height or weight values were categorized as missing for the BMI variable $(3.5 \%)$. Undocumented TOF data were analysed as a separate category. To assess current usage of neostigmine, patient and case characteristics were summarized with frequency counts and percentages. Age was normally distributed and reported as means and standard deviations, while surgical case duration (minutes) was not normally distributed and reported as medians and interquartile ranges. Overall trend in neostigmine administration and subjective train-of-four (TOF) documentation was examined quarterly during the study period. For the primary objective, percentages of cases receiving neostigmine (initial dose, second dose, third dose and total dose) and median doses administered for each subjective train-of-four (TOF) category were calculated, as well as minutes between NMB dose, neostigmine administration and extubation. The relationship between NMB dose in ED95 equivalents and TOF categories were also examined. Correlation coefficients, Pearson chi-square tests and Mann-Whitney tests quantified associations and evaluated statistical significance. A $p$-value of $<0.05$ was considered to be statistically significant. Secondary analyses evaluated associations between NMB dosing and neostigmine administration based on World Health Organization Body Mass Index (BMI) categories.

\section{Results}

Table 1 shows patient and case characteristics for the final 135,633 cases that met inclusion criteria from the total of 166,195 cases studied. The stepwise exclusion process is shown in Fig. 1. Monitoring of the neuromuscular blockade with subjective tactile TOF count has been employed and documented in $83.9 \%(113,869)$, and reversal of $\mathrm{NMB}$ with neostigmine occurred in $86.4 \%(117,123)$ of all cases that used non-depolarizing 


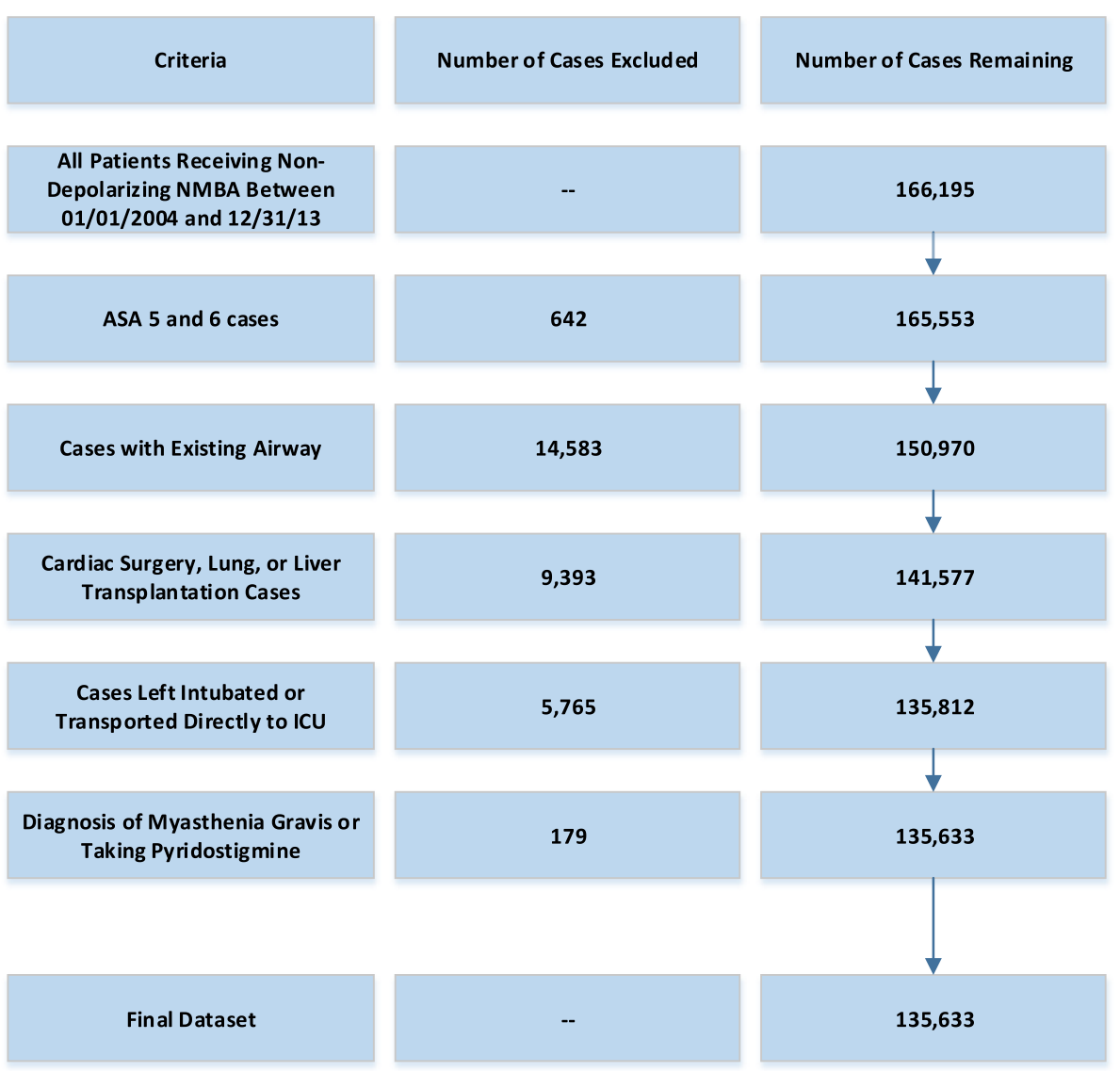

Fig. 1 Study Population Breakdown. NMDA = Neuromuscular Blocking Agent

NMB agents. Of the 18,510 cases who did not receive neostigmine, $69.7 \%$ had no documentation of monitoring. Contrary to our original hypothesis, there was no clinically significant difference in median neostigmine dosing based on last TOF count prior to reversal administration: $37.5 \mathrm{mcg} / \mathrm{kg}$ [range $3.8-125 \mathrm{mcg} / \mathrm{kg}$ ] for TOF of $4 / 4 \mathrm{vs} 37.0 \mathrm{mcg} / \mathrm{kg}$ [range $5.0-95.7 \mathrm{mcg} / \mathrm{kg}$ ] for TOF $0 / 4$ for the initial neostigmine dose and $37.5 \mathrm{mcg} / \mathrm{kg}$ for TOF of $4 / 4$ vs. $37.9 \mathrm{mcg} / \mathrm{kg}$ for TOF of $0 / 4$ for the total neostigmine dose. However, significantly higher number of patients with lower TOF counts received additional neostigmine administration: $5.7 \%$ for $0 / 4$ TOF, $5.2 \%$ for $1 / 4$ TOF, $3.6 \%$ for $2 / 4$ TOF, $2.5 \%$ for $3 / 4$ TOF, and $1.5 \%$ for $4 / 4$ TOF counts (combined $2^{\text {nd }}$ and $3^{\text {rd }}$ neostigmine doses). In addition to the 3.8-fold difference in extra reversal between highest and lowest TOF categories $(p<.0001)$, patients with TOF of $4 / 4$ received a significantly lower median neostigmine dose of $14.7 \mathrm{mcg} /$ $\mathrm{kg}$ [range $3.4-60.6 \mathrm{mcg} / \mathrm{kg}$ ] compared to $20.0 \mathrm{mcg} / \mathrm{kg}$ [range $5.6-61.3 \mathrm{mcg} / \mathrm{kg}$ ] for patients in the TOF $0 / 4$ category $(p<.0001)$ (based on $2^{\text {nd }}$ neostigmine dose only). These results are summarized in Table 2 . There was little correlation between the total dose of NMB agents in
ED95 equivalents and TOF categories: 3.5 for TOF of $0 /$ 4 and $4 / 4$ and 4.0 for TOF $1-3 / 4(\mathrm{r}=-0.08795)$. The median times between administration of the first reversal dose and extubation were not clinically significant between TOF categories: $12.7 \mathrm{~min}$ for $4 / 4 \mathrm{TOF}$ and $12.0 \mathrm{~min}$ for $0 / 4$ TOF counts. These findings are summarized in Table 3. The trends in neostigmine use and TOF monitoring are shown in Fig. 2 and demonstrate increase in percentage of cases getting reversal from $76.2 \%$ in 2004 to $92.2 \%$ in 2013 , as well as a significant increase from 51.9 to $79.0 \%$ in cases with last TOF count of 3 or 4 out of 4 prior to reversal. The overall use of subjective TOF monitoring has increased from 73.0 to $87.8 \%$ over the ten year study period.

The median doses for neostigmine based on TBW decreased with higher BMI categories and were significantly different between the lowest (Underweight, BMI <18.5) and highest (Class III Obese, BMI $\geq 40$ ) categories: $42.6 \mathrm{mcg} / \mathrm{kg}$ vs $30.5 \mathrm{mcg} / \mathrm{kg}$ for initial doses $(p<.0001)$ and $42.8 \mathrm{mcg} / \mathrm{kg}$ vs $30.8 \mathrm{mcg} / \mathrm{kg}$ for total doses $(p<.0001)$ respectively (Table 2$)$. The percentages of cases requiring reversal in addition to the initial dose $\left(2^{\text {nd }}\right.$ and $3^{\text {rd }}$ neostigmine doses combined) increased with increasing 
Table 2 Neostigmine dose by last documented Train of Four (TOF) prior to reversal and Body Mass Index (BMI) category for cases receiving Neostigmine

\begin{tabular}{|c|c|c|c|c|c|c|c|c|c|}
\hline & $\begin{array}{l}\text { Cases receiving } \\
\text { first dose }\end{array}$ & Initial dose (mcg/kg) & $\begin{array}{l}\text { Cases receiving } \\
\text { second dose }\end{array}$ & $\begin{array}{l}\text { Time between } \\
\text { first and second } \\
\text { doses (minutes) }\end{array}$ & $\begin{array}{l}\text { Second dose } \\
(\mathrm{mcg} / \mathrm{kg})\end{array}$ & $\begin{array}{l}\text { Cases receiving } \\
\text { third dose }\end{array}$ & $\begin{array}{l}\text { Time between second } \\
\text { and third doses (minutes) }\end{array}$ & Third dose $(\mathrm{mcg} / \mathrm{kg})$ & Total dose $(\mathrm{mcg} / \mathrm{kg})$ \\
\hline & $N^{a}$ & Median [IQR] & $N(\%)^{a}$ & Median [IQR] & Median [IQR] & $N(\%)^{a}$ & Median [IQR] & Median [IQR] & Median [IQR] \\
\hline \multicolumn{10}{|c|}{ Last TOF prior to reversal } \\
\hline $0 / 4$ & 3520 & $37.0[30.6,42.4]$ & $192(5.5)$ & $6[2,12]$ & $20.0[14.2,28.1]$ & $7(0.2)$ & $5[3,8]$ & $22.4[13.0,23.9]$ & $37.9[30.9,43.7]$ \\
\hline $1 / 4$ & 6956 & $37.1[30.8,42.8]$ & $338(4.9)$ & $6[2,11]$ & $17.3[11.6,24.8]$ & $18(0.3)$ & $6[3,14]$ & $16.8[13.8,27.8]$ & $37.8[31.3,43.9]$ \\
\hline $2 / 4$ & 7713 & $37.2[30.9,42.2]$ & $267(3.5)$ & $7[2,13]$ & $15.8[10.8,25.0]$ & $11(0.1)$ & $7[2,9]$ & $11.1[8.1,18.1]$ & $37.6[31.1,42.7]$ \\
\hline $3 / 4$ & 7133 & $36.8[30.7,41.9]$ & $166(2.3)$ & $5[1,12]$ & $14.5[10.1,22.3]$ & $11(0.2)$ & $7[3,10]$ & $14.7[10.6,17.9]$ & $37.0[30.8,42.3]$ \\
\hline $4 / 4$ & 81,958 & $37.5[30.6,41.7]$ & $1136(1.4)$ & $5[1,12]$ & $14.7[9.9,22.1]$ & $73(0.1)$ & $3[1,6]$ & $11.3[9.3,15.2]$ & $37.5[30.6,41.7]$ \\
\hline Undocumented & 9105 & $34.5[29.4,41.1]$ & $217(2.4)$ & $6[2,11]$ & $17.9[11.1,26.7]$ & $10(0.1)$ & $9[4,16]$ & $14.1[11.6,17.5]$ & $35.0[29.4,41.5]$ \\
\hline \multicolumn{10}{|l|}{ WHO BMI category ${ }^{\mathrm{b}}$} \\
\hline Underweight & 2456 & $42.6[36.6,49.2]$ & $50(2.0)$ & $10[4,15]$ & $22.7[19.3,31.3]$ & $1(0.0)$ & $15[15,15]$ & $24.1[24.1,24.1]$ & $42.8[36.8,50.0]$ \\
\hline Normal weight & 32,491 & $39.4[33.3,44.4]$ & $574(1.8)$ & $6[2,12]$ & $19.2[14.4,29.9]$ & $31(0.1)$ & $6[2,9]$ & $17.2[14.3,23.9]$ & $39.7[33.4,44.8]$ \\
\hline Overweight & 35,302 & $37.5[31.1,41.7]$ & $609(1.7)$ & $6[1,11]$ & $15.6[11.9,25.5]$ & $42(0.1)$ & $5[2,10]$ & $13.2[10.8,20.0]$ & $37.6[31.3,41.7]$ \\
\hline Class I obese & 22,634 & $35.3[29.7,40.4]$ & $488(2.2)$ & $5[1,13]$ & $14.4[10.1,22.2]$ & $26(0.1)$ & $3[1,7]$ & $10.5[9.4,12.8]$ & $35.7[29.8,40.7]$ \\
\hline Class II obese & 11,321 & $32.7[28.1,39.7]$ & $258(2.3)$ & $4[1,11]$ & $11.9[9.2,19.6]$ & $14(0.1)$ & $2[1,5]$ & $10.3[9.0,13.6]$ & $33.1[28.4,40.0]$ \\
\hline Class III obese & 8973 & $30.5[25.0,37.0]$ & 284 (3.2) & $3[0,9]$ & $10.4[7.5,16.7]$ & $12(0.1)$ & $4[1,11]$ & $8.1[7.0,14.3]$ & $30.8[25.3,37.5]$ \\
\hline
\end{tabular}

TOF train-of-four, WHO World Health Organization, $B M I$ body mass index

anly among patients with TBW between 40 and $250 \mathrm{~kg}$ and receiving neostigmine

bOnly among patients with BMI between 10 and 80 
Table 3 Neuromuscular Blocking Agent dose by last documented Train-of-Four prior to reversal and Body Mass Index category

\begin{tabular}{|c|c|c|c|c|}
\hline & $\begin{array}{l}\text { Total dose of NMB } \\
\text { (ED } 95 \text { equivalent })^{a}\end{array}$ & $\begin{array}{l}\text { Last dose of NMB } \\
\text { (ED } 95 \text { equivalent) }^{\mathrm{a}}\end{array}$ & $\begin{array}{l}\text { Time between last NMB \& first } \\
\text { neostigmine dose (minutes) }\end{array}$ & $\begin{array}{l}\text { Time between first neostigmine } \\
\text { dose \& extubation (minutes) }\end{array}$ \\
\hline & Median [IQR] & Median [IQR] & Median [IQR] & Median [IQR] \\
\hline \multicolumn{5}{|c|}{ Last TOF prior to reversal } \\
\hline $0 / 4$ & $3.5[2.4,5.2]$ & $1.3[0.7,2.4]$ & $52.0[36.0,80.3]$ & $12.0[8.0,18.0]$ \\
\hline $1 / 4$ & $4.0[2.8,5.8]$ & $0.8[0.5,1.7]$ & $42.0[29.0,59.0]$ & $12.5[8.0,19.0]$ \\
\hline $2 / 4$ & $4.0[2.8,5.9]$ & $0.7[0.4,1.4]$ & $43.6[31.0,61.0]$ & $12.8[8.0,18.9]$ \\
\hline $3 / 4$ & $4.0[2.7,5.8]$ & $0.7[0.4,1.5]$ & $49.0[35.0,68.0]$ & $12.4[8.0,19.0]$ \\
\hline $4 / 4$ & $3.5[2.5,5.3]$ & $0.8[0.5,1.8]$ & $65.0[44.0,95.0]$ & $12.7[8.0,19.0]$ \\
\hline Undocumented & $3.3[2.2,5.1]$ & $0.7[0.4,1.8]$ & $43.0[24.0,76.0]$ & $12.0[7.3,18.0]$ \\
\hline \multicolumn{5}{|l|}{ WHO BMI category ${ }^{c}$} \\
\hline Underweight & $2.9[2.0,4.4]$ & $0.8[0.5,1.6]$ & $57.4[39.0,86.4]$ & $13.8[9.0,21.0]$ \\
\hline Normal Weight & $3.3[2.2,4.9]$ & $0.8[0.4,1.8]$ & $58.0[39.0,86.0]$ & $13.0[8.0,19.0]$ \\
\hline Overweight & $3.6[2.5,6.3]$ & $0.7[0.4,1.8]$ & $58.9[39.0,87.9]$ & $12.1[8.0,19.0]$ \\
\hline Class I Obese & $3.8[2.7,5.7]$ & $0.8[0.5,1.9]$ & $59.0[39.0,87.5]$ & $12.1[8.0,19.0]$ \\
\hline Class II Obese & $4.0[2.7,5.9]$ & $0.8[0.5,2.0]$ & $58.5[39.1,88.1]$ & $12.3[8.0,19.0]$ \\
\hline Class III Obese & $4.2[2.9,6.3]$ & $0.8[0.5,1.9]$ & $57.0[38.0,85.0]$ & $12.9[8.0,19.0]$ \\
\hline
\end{tabular}

ED95 effect dose for which $95 \%$ of the population exhibits the effect, TOF train-of-four, WHO World Health Organization, BMI body mass index aOnly among patients with IBW between 40 and $250 \mathrm{~kg}$

${ }^{b}$ Only among patients receiving neostigmine

'Only among patients with BMI between 10 and 80

BMI categories and were $2.1 \%$ for $\mathrm{BMI}<18$ vs. $3.3 \%$ for $\mathrm{BMI} \geq 40$. The total median dose of $\mathrm{NMB}$ agents in ED95 equivalents per IBW increased from 2.9 in the Underweight category to 4.2 in the Class III Obese category (Table 3 ). The variations in the administration of neostigmine and NMB agents across different BMI categories are represented graphically in Fig. 3. The time intervals between initial neostigmine administration and extubation were clinically similar (within one minute) across the BMI categories.

Analysis of subgroups based on individual NMB agents, showed that only $31.9 \%$ of patients receiving pancuronium were reversed with neostigmine, compared to 75.9-89.2 \% for other non-depolarizing NMB agents. The median dose of pancuronium in ED95 equivalents was 0.1 in the group that did not

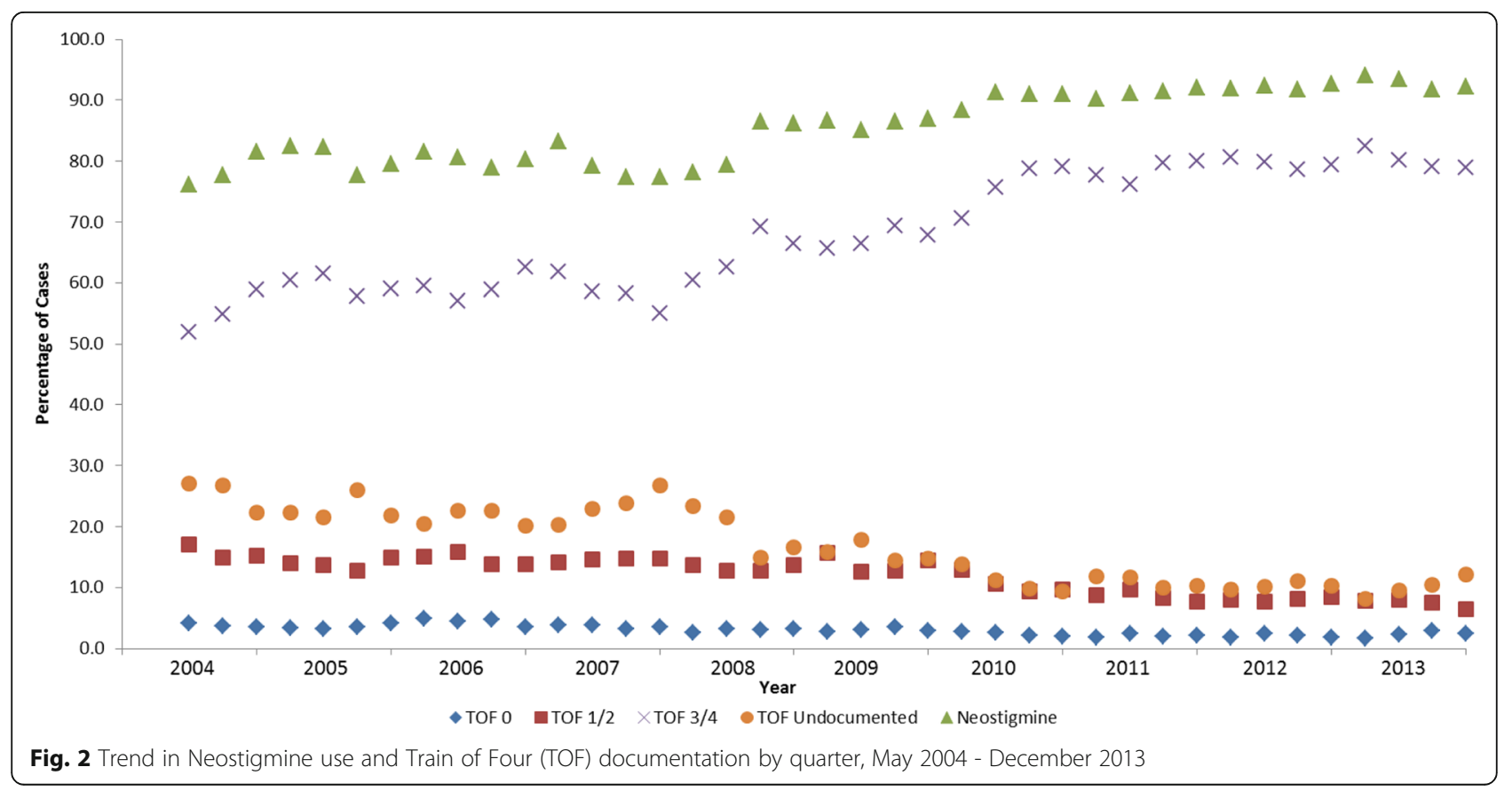




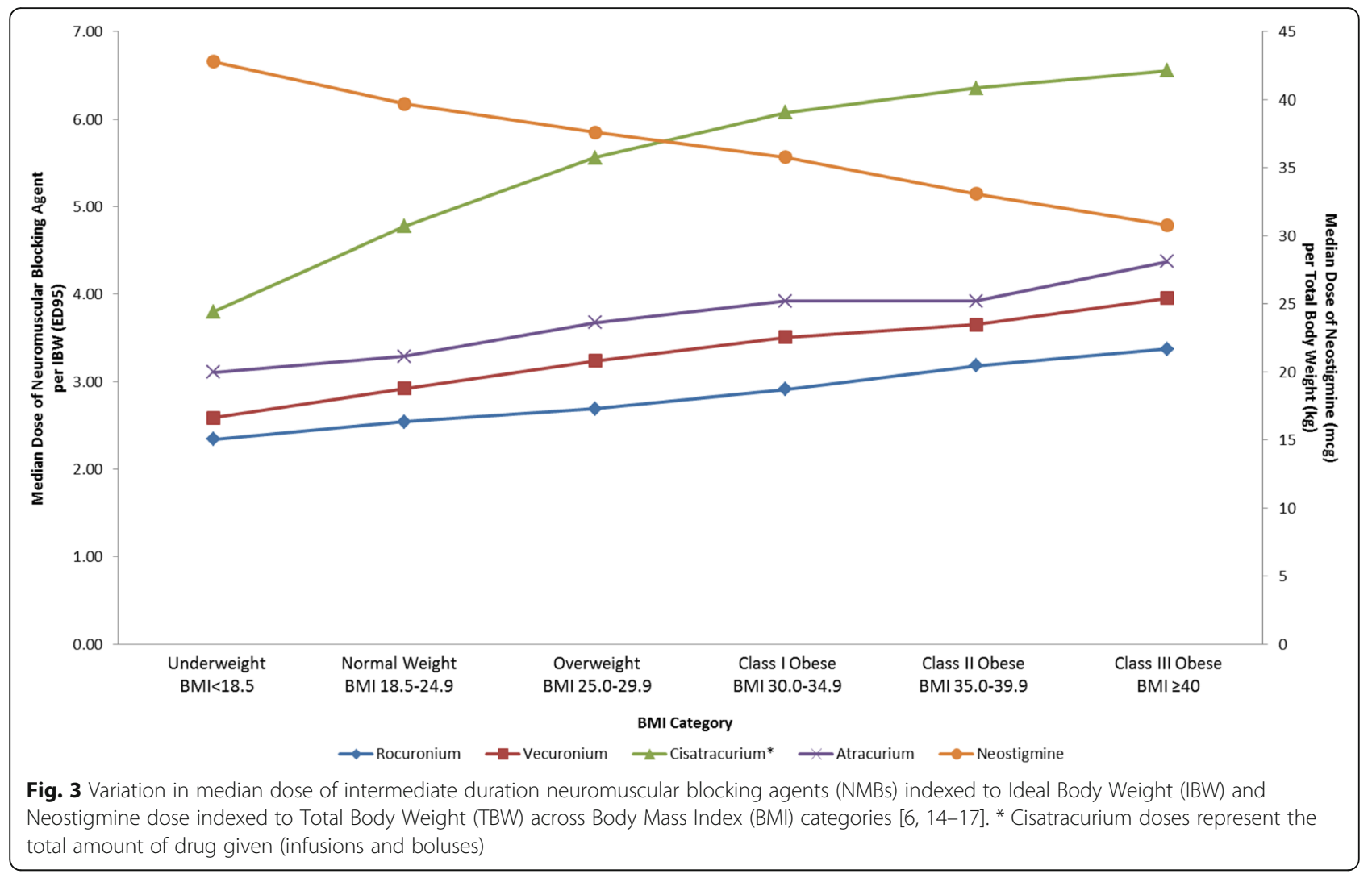

receive reversal, likely consistent with practice of precurarization (Table 4). The median reversal dose for patients receiving pancuronium was significantly higher than neostigmine doses for intermediate acting neuromuscular blockers: $47.2 \mathrm{mcg} / \mathrm{kg}$ vs $33.7-38.2$ $\mathrm{mcg} / \mathrm{kg}$. Subgroup analysis also demonstrated that patients receiving cisatracurium had significantly higher median ED95 equivalent dose of 5.6 vs 2.8-3.9 compared to other intermediate acting NMB agents, while receiving clinically similar doses of neostigmine 36 $\mathrm{mcg} / \mathrm{kg}$ vs $33.7-38.2 \mathrm{mcg} / \mathrm{kg}$ (Table 4 , no succinylcholine). Similar trend was observed for subgroups receiving cisatracurium and no reversal, both with and without succinylcholine.

\section{Discussion}

In this large, single-centre study we demonstrate that contrary to the published guidelines and our hypothesis, there was little correlation between monitoring of the depth of neuromuscular blockade and dosing of neostigmine in clinical practice. The total neostigmine dose tended to be weight-based and fell into a narrow clinical range of $37.0-37.9 \mathrm{mcg} / \mathrm{kg}$ across all TOF categories and was significantly lower than the "standard dose" of $50 \mathrm{mcg} / \mathrm{kg}$ reported by other sources [12, 19] and recommended for reversing TOF counts between 1 and 3 [10]. Although our single centre database may reflect institutional bias and site-specific clinical care processes associated with a large academic medical centre with an anaesthesiology training program, our median reversal doses were remarkably similar to the mean neostigmine dose of $32 \mathrm{mcg} / \mathrm{kg}$ recently reported by Roach and Smith [12].

The median time from reversal administration to extubation also did not change significantly (12.0-12.8 min range) based on the TOF count prior to reversal. Together these findings suggest that when using nondepolarizing NMB agents, the vast majority of providers employed TOF monitoring and administered reversal, however neither neostigmine dosing nor time to extubation were affected by the depth of the neuromuscular blockade prior to reversal. One parameter that correlated strongly with the depth of NMB was the need for additional reversal, or rescue, when initial dose failed to produce desired clinical effect. In addition, $3.0 \%$ of patients received inappropriate reversal when the neostigmine was administered with TOF count of $0 / 4$ [10]. This is markedly lower than reported in recent literature from other single-centre analyses [6]. It was encouraging to see that the overall number of cases receiving clinically-indicated neostigmine has increased throughout the study period, as well as the percentage of cases with TOF counts of $3-4 / 4$. We 
Table 4 Subgroup analysis of individual neuromuscular blocking agents

\begin{tabular}{|c|c|c|c|c|c|c|c|c|}
\hline & \multirow{3}{*}{$\begin{array}{l}\text { Neuromuscular } \\
\text { blocking agent }\end{array}$} & \multicolumn{4}{|c|}{ Cases receiving neostigmine } & \multicolumn{3}{|c|}{ Cases not receiving neostigmine } \\
\hline & & $\begin{array}{l}\text { Cases receiving } \\
\text { NMB }\end{array}$ & $\begin{array}{l}\text { NMB total dose } \\
\text { (ED } 95 \text { Equivalent) }^{\text {a }}\end{array}$ & $\begin{array}{l}\text { Time between last NMB } \\
\text { \& extubation (minutes) }\end{array}$ & $\begin{array}{l}\text { Total dose of neostigmine } \\
(\mathrm{mcg} / \mathrm{kg})^{\mathrm{b}}\end{array}$ & Cases receiving NMB & $\begin{array}{l}\text { NMB total dose } \\
(\text { (ED } 95 \text { Equivalent })^{\text {a }}\end{array}$ & $\begin{array}{l}\text { Time between last } \\
\text { NMB \& extubation } \\
\text { (minutes) }\end{array}$ \\
\hline & & $N$ & Median [IQR] & Median [IQR] & Median [IQR] & N & Median [IQR] & Median [IQR] \\
\hline \multirow[t]{6}{*}{ No Succinylcholine } & Atracurium & 2981 & $3.9[2.6,5.9]$ & $67.0[50.0,90.0]$ & $33.7[29.7,41.7]$ & 906 & $2.9[2.1,4.7]$ & $119.0[85.0,174.0]$ \\
\hline & Cisatracurium & 12,905 & $5.6[3.9,8.3]$ & $73.0[53.0,102.0]$ & $36.0[30.2,42.4]$ & 2596 & $4.6[3.1,7.1]$ & $136.0[90.0,204.0]$ \\
\hline & Pancuronium & 134 & $1.3[0.1,2.3]$ & $99.5[62.0,161.0]$ & $47.2[35.8,61.7]$ & 48 & $0.1[0.1,0.1]$ & $210.5[150.5,265.0]$ \\
\hline & Rocuronium & 5602 & $2.8[2.2,4.0]$ & $83.0[59.0,117.0]$ & $36.6[29.8,41.7]$ & 1510 & $2.4[1.8,3.4]$ & $126.0[89.0,174.0]$ \\
\hline & Vecuronium & 65,708 & $3.4[2.4,4.9]$ & $76.0[55.0,108.0]$ & $38.2[31.5,42.2]$ & 7343 & $2.8[2.0,4.5]$ & $145.0[93.0,233.0]$ \\
\hline & Multiple NMBAs & 1185 & $5.9[4.4,8.0]$ & $71.0[52.0,101.0]$ & $39.0[32.1,44.9]$ & 216 & $6.6[4.8,8.6]$ & $92.0[37.5,162.5]$ \\
\hline \multirow[t]{6}{*}{ Succinylcholine } & Atracurium & 1407 & $3.4[2.2,5.4]$ & $60.0[46.0,84.0]$ & $31.8[28.2,39.0]$ & 439 & $2.5[1.5,4.4]$ & $95.0[65.0,141.0]$ \\
\hline & Cisatracurium & 4591 & $4.8[2.9,7.6]$ & $65.0[49.0,88.0]$ & $32.7[28.8,40.0]$ & 864 & $4.1[2.2,7.5]$ & $106.0[68.0,153.0]$ \\
\hline & Pancuronium & 63 & $2.1[1.2,2.6]$ & $96.0[74.0,140.0]$ & $37.0[31.6,48.0]$ & 1025 & $0.1[0.1,0.1]$ & $101.5[60.0,181.5]$ \\
\hline & Rocuronium & 674 & $2.1[1.3,3.0]$ & $62.0[42.0,87.0]$ & $32.1[26.1,39.4]$ & 232 & $1.0[0.3,2.0]$ & $81.0[53.0,129.0]$ \\
\hline & Vecuronium & 21,514 & $3.0[1.9,4.7]$ & $67.0[49.0,93.0]$ & $36.7[30.0,41.3]$ & 3026 & $2.6[1.3,4.8]$ & $115.0[67.0,195.0]$ \\
\hline & Multiple NMBAs & 359 & $3.6[2.2,5.6]$ & $65.0[46.0,94.0]$ & $35.1[30.0,41.3]$ & 305 & $3.0[1.5,6.3]$ & $82.0[41.0,154.0]$ \\
\hline
\end{tabular}

${ }^{\text {a } O n l y ~ a m o n g ~ p a t i e n t s ~ w i t h ~ I B W ~ b e t w e e n ~} 40$ and $250 \mathrm{~kg}$ 
speculate that this reflects increased awareness of the residual neuromuscular blockade by clinical providers in recent years.

Although median values for neostigmine did not change much based on last TOF counts, there was significant variability in its dosing across the BMI categories. Both categories at the extremes of the BMI spectrum have been shown to be at risk for residual neuromuscular blockade [7] or postoperative pulmonary complications: $6.39 \%$ for BMI $<18$ and $4.15 \%$ for $\mathrm{BMI}>35$ vs. $3.61 \%$ for normal weight patients [6]. A recent study by Sasaki et al. [21] demonstrated that high-dose or unwarranted use of neostigmine may be associated in increased incidence of postoperative respiratory events. Further evidence that reversal with acetylcholine inhibitors may be undesirable in the absence of neuromuscular blockade was provided by Herbstreit et al. [22], supporting the idea that reversal dose must be closely matched to the depth of the existing NMB [10]. Our data suggest that different mechanisms may be responsible for the higher reported incidence of adverse events in underweight and severely overweight patients. As Fig. 3 demonstrates, underweight patients tend to receive relatively lower NMB doses while simultaneously receiving relatively higher reversal doses, potentially placing them at an increased risk from excessive use of acetylcholine inhibitors. The opposite is true for patients with BMI > 40, who may be at higher risk due to overdosing of $\mathrm{NMB}$ and relative underdosing of neostigmine. This situation may not be unique to neostigmine, as both recurarization and incomplete reversal with appropriate does of sugammadex have been reported in obese patients receiving high doses of rocuronium [23, 24]. Our findings of potential NMB depth/reversal mismatch across BMI categories raise interesting questions and warrant further investigation through prospective trials.

There are several limitations inherent in this observational analysis of routinely collected intraoperative electronic health record data. First, the analyzed dataset of patient characteristics and intraoperative documentation did not allow for correlation between dose of neostigmine and postoperative clinical outcomes such as reintubation, pneumonia, or atelectasis. In addition, because the standard process of care at our centre, and many others, does not include monitoring of objective acceleromyography, the analysis cannot establish whether the dose of neostigmine is associated with complete reversal. Another limitation of our analysis is the inability to evaluate the impact of common medical comorbidities, the use of volatile anesthesia, or site of monitoring on the patterns of reversal.
Our study provides important information on current clinical patterns of use of neostigmine and exposes discrepancies between existing guidelines and actual clinical practice. In may be useful to incorporate our findings of potential NMB depth/reversal mismatch into design of future trials, as well as to influence future clinical guidelines, since patients in different BMI categories may require different interventions to improve safety of neuromuscular blockade.

\section{Conclusions}

Contrary to our initial hypothesis, deeper levels of neuromuscular blockade were not associated with larger reversal doses. The median neostigmine dosing remained clinically similar across different levels of NMB as defined by the TOF counts. The median times to extubation following neostigmine administration were also similar for all TOF count categories. On the other hand, there was significant variability in neuromuscular blocker and neostigmine dosing across different BMI categories. The total median dose of neuromuscular blocking agents increased with increasing BMI, while the median dose of neostigmine decreased with increasing BMI.

\section{Abbreviations \\ AIMS: Anaesthesia Information Management System; ASA: American Society of Anaesthesiologists; BMI: Body mass index; ED95: Effect dose for which $95 \%$ of the population exhibits the effect; EHR: Electronic health record; IBW: Ideal body weight; ICU: Intensive care unit; NMB: Neuromuscular blockade; OR: Operating room; SAS: Statistical Analysis System; SPSS: Software Package for Statistical Analysis; TBW: Total body weight; TOF: Train of four monitoring; UMHS: University of Michigan Health System; WHO: World Health Organization}

\section{Acknowledgements}

All health record data and analysis are attributed to the Department of Anaesthesiology at the University of Michigan Medical School (Ann Arbor, Michigan).

\section{Funding}

The funding for this study was provided by Merck, Sharp, and Dohme, Inc. (Whitehouse Station, NJ).

\section{Availability of data and materials}

The datasets generated and/or analysed during the current study are available from the corresponding author on reasonable request.

\begin{abstract}
Authors' contributions
TD and SK were involved with the study design, review and analysis of data, manuscript preparation and the decision to submit the manuscript for publication. MH was involved in study design, analysis of data and manuscript preparation. SD, PhD, an employee of Merck, Sharp, and Dohme, Inc., was involved with the study design, drafting of the manuscript and the decision to submit the manuscript for publication. All authors read and approved the final manuscript.
\end{abstract}

Competing interests

The authors declare that they have no competing interests.

Consent for publication

Not applicable - no identifiable details, images, or videos of individual participants were used in this study. 


\section{Ethics approval and consent to participate}

This study received approval from the University of Michigan Institutional Review Board (HUM00091819). The informed consent was waived since all identifiable patient elements were removed prior to data analysis.

\section{Author details}

'Department of Anaesthesiology, University of Michigan Medical School, CVC 4172, 1500 East Medical Centre Drive, Ann Arbour, Ml 48109, USA. ${ }^{2}$ Merck, Sharp, and Dohme, Inc, P.O. Box 100, Whitehouse Station, NJ 08889-0100, USA.

Received: 17 December 2015 Accepted: 9 October 2016

Published online: 22 October 2016

\section{References}

1. Brull SJ, Murphy GS. Residual neuromuscular block: lessons unlearned. Part II: methods to reduce the risk of residual weakness. Anesth Analg. 2010; 111(1):129-40.

2. Murphy GS, Brull SJ. Residual neuromuscular block: lessons unlearned. Part I: definitions, incidence, and adverse physiologic effects of residual neuromuscular block. Anesth Analg. 2010;111(1):120-8.

3. Eikermann $\mathrm{M}$, Groeben $\mathrm{H}$, Husing J, Peters J. Accelerometry of adductor pollicis muscle predicts recovery of respiratory function from neuromuscular blockade. Anesthesiology. 2003:98(6):1333-7.

4. Murphy GS, Szokol JW, Avram MJ, Greenberg SB, Marymont JH, Vender JS, Gray J, Landry E, Gupta DK. Intraoperative acceleromyography monitoring reduces symptoms of muscle weakness and improves quality of recovery in the early postoperative period. Anesthesiology. 2011;115(5):946-54

5. Grosse-Sundrup M, Henneman JP, Sandberg WS, Bateman BT, Uribe JV, Nguyen NT, Ehrenfeld JM, Martinez EA, Kurth T, Eikermann M. Intermediate acting non-depolarizing neuromuscular blocking agents and risk of postoperative respiratory complications: prospective propensity score matched cohort study. BMJ. 2012;345:e6329.

6. McLean DJ, Diaz-Gil D, Farhan HN, Ladha KS, Kurth T, Eikermann M. Dosedependent Association between Intermediate-acting Neuromuscularblocking Agents and Postoperative Respiratory Complications. Anesthesiology. 2015;122(6):1201-13.

7. Fortier LP, McKeen D, Turner K, de Medicis E, Warriner B, Jones PM, Chaput A Pouliot JF, Galarneau A. The RECITE Study: A Canadian Prospective, Multicenter Study of the Incidence and Severity of Residual Neuromuscular Blockade. Anesth Analg. 2015;121(2):366-72.

8. Naguib M, Kopman AF, Lien CA, Hunter JM, Lopez A, Brull SJ. A survey of current management of neuromuscular block in the United States and Europe. Anesth Analg. 2010;111(1):110-9.

9. Videira RL, Vieira JE. What rules of thumb do clinicians use to decide whether to antagonize nondepolarizing neuromuscular blocking drugs? Anesth Analg. 2011;113(5):1192-6.

10. Kopman AF, Eikermann M. Antagonism of non-depolarising neuromuscular block: current practice. Anaesthesia. 2009;64 Suppl 1:22-30.

11. Farhan H, Moreno-Duarte I, McLean D, Eikermann M. Residual paralysis: does it influence outcome after ambulatory surgery? Curr Anesthesiol Rep. 2014:4(4):290-302

12. Roach B, Smith NA. Neostigmine dose: comparison between theory and practice. Eur J Anaesthesiol. 2015;32:742.

13. Baillard C, Clec'h C, Catineau J, Salhi F, Gehan G, Cupa M, Samama CM. Postoperative residual neuromuscular block: a survey of management. Br J Anaesth. 2005:95(5):622-6.

14. Barash PG, Cullen BF, Stoelting RK, Cahalan MK, Stock MC, Ortega R. Handbook of Clinical Anesthesia. 7th ed. Philadelphia: Wolters Kluwer Health; Lippincott Williams \& Wilkins; 2013.

15. Joshi SB, Upadhyaya KV, Manjuladevi M. Comparison of neostigmine induced reversal of vecuronium in normal weight, overweight and obese female patients. Indian J Anaesth. 2015;59(3):165-70.

16. van Kralingen S, van de Garde EM, Knibbe CA, Diepstraten J, Wiezer MJ, van Ramshorst B, van Dongen EP. Comparative evaluation of atracurium dosed on ideal body weight vs. total body weight in morbidly obese patients. Br J Clin Pharmacol. 2011;71(1):34-40.

17. De Baerdemaeker LE, Mortier EP Struys MM. Pharmacokinetics in obese patients. Cont Educ Anaesth Crit Care Pain. 2004;4(5):152-5.
18. Kirkegaard-Nielsen $H$, Lindholm $P$, Petersen HS, Severinsen IK. Antagonism of atracurium-induced block in obese patients. Can J Anaesth. 1998:45:39-41.

19. Naguib M, Lien CA. Pharmacology of muscle relaxants and their antagonists. In: Miller RD, Eriksson LI, Fleisher L, Wiener-Kronish JP, Young WL, editors. Miller's Anesthesia. 7th ed. Philadelphia: Churchill Livingstone; 2009. p. 859-911.

20. Shanks CA. Pharmacokinetics of the nondepolarizing neuromuscular relaxants applied to calculation of bolus and infusion dosage regimens. Anesthesiology. 1986;64(1):72-86

21. Sasaki N, Meyer MJ, Malviya SA, Stanislaus AB, MacDonald T, Doran ME, lgumenshcheva $\mathrm{A}$, Hoang $\mathrm{AH}$, Eikermann $\mathrm{M}$. Effects of neostigmine reversal of nondepolarizing neuromuscular blocking agents on postoperative respiratory outcomes: a prospective study. Anesthesiology. 2014;121(5):959-68.

22. Herbstreit F, Zigrahn D, Ochterbeck C, Peters J, Eikermann M. Neostigmine/ glycopyrrolate administered after recovery from neuromuscular block increases upper airway collapsibility by decreasing genioglossus muscle activity in response to negative pharyngeal pressure. Anesthesiology. 2010;113(6):1280-8.

23. Kayashima K, Sozen R, Okura D. Insufficient sugammadex effect in an obese pregnant woman undergoing cesarean section under general anesthesia. Masui. 2014;63(2):188-90.

24. Le Corre F, Nejmeddine S, Fatahine C, Tayar C, Marty J, Plaud B. Recurarization after sugammadex reversal in an obese patient. Can J Anaesth. 2011:58(10):944-7.

\section{Submit your next manuscript to BioMed Central and we will help you at every step:}

- We accept pre-submission inquiries

- Our selector tool helps you to find the most relevant journal

- We provide round the clock customer support

- Convenient online submission

- Thorough peer review

- Inclusion in PubMed and all major indexing services

- Maximum visibility for your research

Submit your manuscript at www.biomedcentral.com/submit
Biomed Central 